\title{
O fenômeno informacional indígena e o processo de documentação
}

\author{
The indigenous informational phenomenon and the documentation process
}

\begin{abstract}
Rodrigo Piquet Saboia de Mello
Doutorando em Ciência da Informação pelo Programa de Pós-Graduação em Ciência da Informação do Instituto Brasileiro de Informação em Ciência e Tecnologia - IBICT/Universidade Federal do Rio de Janeiro - UFRJ.

Chefe do Núcleo de Informação Científica do Museu do Índio.

E-mail: nuic@museudoindio.gov.br
\end{abstract}

\section{Resumo}

Este artigo procura refletir as relações existentes entre as informações contidas nos repositórios públicos do Estado brasileiro referentes à temática indígena, as diretrizes que norteiam o trabalho indigenista e do processo de autonomia informacional dos povos indígenas. Este processo de criação documental gerou num primeiro momento o poder de controle do Estado sobre os povos indígenas, e, posteriormente, o mesmo grupo que havia sido vigiado e controlado pode se apoderar das ferramentas criadas pelo próprio Estado para se empoderarem e lutarem de maneira qualificada para a conquista e manutenção de seus territórios e de suas especificidades culturais.

Palavras-chave: Documentação etnológica. Protagonismo indígena. Autonomia informacional.

\begin{abstract}
This article tries to reflect the existing relations between the information contained in the public repositories of the Brazilian State regarding the indigenous theme, the guidelines that guide the indigenous work and the process of informational autonomy of the indigenous peoples. This process of documentary creation first created the power of state control over indigenous peoples, and later the same group that had been monitored and controlled could seize the tools created by the state itself to empower and fight in a qualified way for the conquest and maintenance of their territories and their cultural specificities.
\end{abstract}

Keywords: Ethnological documentation. Indigenous protagonism. Informational autonomy. 


\title{
1. Introdução
}

A ação do Estado brasileiro para com os indígenas em seu território tem início no ano de 1910, com a criação do Serviço de Proteção aos Índios e Localização dos Trabalhadores Nacionais (SPILTN) e nesta efeméride há como marco o início da relação laica entre o Estado e os indígenas. Até então, o que havia era uma relação mediada pela Igreja Católica e a sua ação catequética.

A relação entre catequese ou proteção eclesiástica estava na gênese do elo com os povos indígenas e os desdobramentos resultantes desta ação. Deste modo:

\begin{abstract}
Em meio a estes debates, o País toma consciência do problema indígena, definindose $\log$ duas correntes opostas. Uma, religiosa, que defendia a catequese católica como a única solução compatível com a formação do povo brasileiro. Outra, leiga, argumentava que a assistência protetora ao índio competia privativamente ao Estado. Sendo este leigo, leiga devia ser a assistência mesmo porque mais de uma religião era professada pelo povo e cabia assegurar ao índio plena liberdade de consciência para, uma vez capacitado, escolher sua própria fé, e bem assim garantir a todas as confissões religiosas o direito de fazer prosélitos entre eles. (RIBEIRO, 1962, p. 13)
\end{abstract}

Ganhando a tese da chamada proteção do Estado, com a formação de uma agência estatal específica voltada para as questões indígenas no florescer da república brasileira, foi possível verificar o início do acúmulo documentário em repositórios que refletiam os atos emanados do Estado para com a população ameríndia. Deste modo, a documentação comprova em diversas circunstâncias a presença de indígenas em território brasileiro e a memorialidade desses povos.

A documentação hoje acumulada possui uma história de muitos revezes e uma trajetória de quase perda. Vejamos:

Em 16 de junho de 1967, um incêndio destruiu sete andares do edifício do Ministério da Agricultura, em Brasília, transformando em cinzas arquivos administrativos, filmes, mapas, gravações e artefatos depositados na sede do Serviço de Proteção aos Índios (SPI). Na época, o incêndio "suspeito" foi tido por algumas personalidades como criminoso, uma 'queima de arquivo', já que ocorrera após a instalação da Comissão Parlamentar de Inquérito do SPI pelo Ministro do Interior, General Albuquerque Lima. (FREIRE, 2011, p. 11)

Destarte, boa parte da documentação esteve praticamente perdida, tendo sido necessários esforços para recuperar documentos dispersos em regiões do país, com ações de recolhimento nas então denominadas Administrações Regionais da Fundação Nacional do Índio (FUNAI) por técnicos do Museu do Índio (MI), instituição de natureza técnico-científica da supracitada Fundação. Em meados dos anos de 1970, temos a criação do Centro de 
Documentação Etnológica (CDE), que teria um papel fundamental na construção deste repositório de documentos. Vejamos quais seriam as funções do Centro:

1) A criação de um sistema de arquivo que priorizasse a salvaguarda, o controle e a organização de toda e qualquer documentação, em particular a de interesse etnológico e indigenista, que contemplasse a totalidade da documentação sob a esfera da FUNAI e reunisse os arquivos de outras instituições relacionadas ao contato com os povos indígenas, tendo em vista a "reconstrução" do acervo perdido em 1967;

2) A organização de um arquivo para cada grupo indígena, com informações úteis para a pesquisa etnológica e documentos de natureza legal referentes às suas terras;

3) A formulação de um programa sistemático de pesquisas etno-históricas. (MOREIRA NETO, 1979, p. 13)

Mesmo com o importante trabalho de reunir a documentação dispersa pelo território brasileiro, os arquivos se encontravam no que podemos chamar de caos documentário, conceito este elaborado pelo documentalista Bradford (1961), que sintetiza um acúmulo não programado de documentação gerada por uma entidade produtora.

Desde já, é possível afirmar que uma das maiores garantias que o recolhimento e a salvaguarda desta documentação pode trazer é a salvaguarda das terras indígenas. Os territórios indígenas devem estar embasados numa documentação para que tenha a possibilidade de resgatar a memória da presença dos povos indígenas numa determinada localidade do país e sua possível transformação em terra indígena reconhecida pelo Estado brasileiro.

Estes documentos podem representar uma incorporação de povos excluídos do processo gerado com a democratização do Estado brasileiro. Portanto:

\footnotetext{
É dentro desse quadro conceitual que vem sendo usualmente tratada a questão da incorporação dos povos indígenas às sociedades nacionais, focalizada por meio das diferentes esferas de contradições e impasses (econômicos, político-jurídicos, socioculturais e éticos) que suscita. Mas a realidade atual é de um mundo globalizado no qual as sociedades mantêm fronteiras porosas, são atravessadas por múltiplos processos de diásporas e operam uma revalorização de identidades e saberes locais. (OLIVEIRA, 2002, p. 105)
}

Esta incorporação à qual Oliveira se refere ocorre em diversos níveis, como a garantia às terras tradicionalmente ocupadas, o acesso aos serviços de saúde e também ao acervo documental referente à história destes povos. Este conhecimento se tornou um fator fundamental de desenvolvimento das potencialidades dos povos indígenas, como também do acesso às informações que remontam, por exemplo, a constituição da cultura material que determina a que povo pertence um determinado indivíduo. 


\title{
2. Informação, arquivos e indigenismo
}

Começamos pela concepção de Delmas sobre a importância dos arquivos como documento probatório:

\begin{abstract}
Os arquivos servem para provar. A prova, a necessidade da prova frente à justiça foi, na sociedade ocidental, a primeira razão da conservação para longa duração de determinados documentos escritos: diplomas merovíngios e carolíngios, atos, títulos etc. Os documentos conservados eram documentos de arquivo porque probatórios, e não o contrário. Só muito mais tarde é que foram reconhecidos a todo documento de arquivo um caráter de autenticidade e um valor probatório a ser preservado. (DELMAS, 2010, p. 21)
\end{abstract}

As informações inseridas nos arquivos que têm como objeto a temática indígena servem de grande valor pra a compreensão das dinâmicas produzidas entre estes povos e o Estado brasileiro. Porém, contemporaneamente, a sua importância cresceu em larga escala, já que os documentos detêm um valor probatório junto a tribunais brasileiros, por exemplo, estabelecendo deste modo uma relação de veracidade de fatos produzidos num determinado contexto histórico.

No que tange à demarcação das terras indígenas, o valor probatório dos documentos se faz mais importante, pois é a partir dos elementos de veracidade contidos nos arquivos indigenistas que vamos encontrar a comprovação da permanência de povos em localidades muitas vezes pleiteadas ora por fazendeiros, ora por mineradoras ou por outros interessados na expansão econômica assimétrica do país. Cabe ainda frisar que estas expansões, em muitos casos, não são respeitados os direitos dos povos originários, ocorrendo violência nas áreas de conflito.

Outro caso de importância da produção documentação estatal de natureza indigenista se refere ao grupo indígena Pataxó. A organização do inventário dos documentos do Posto Indígena Caramuru-Paraguaçu (1910-1967) reativou vozes esquecidas por gestores públicos baianos que emitiam títulos de propriedade dentro da localidade de ocupação tradicional do povo indígena em destaque. A recuperação e organização destes arquivos originários do Serviço de Proteção aos Índios (SPI), instituição do Estado brasileiro que antecedeu a FUNAI, gerou uma renovação nas esperanças de obter as suas terras de direito. O referido inventário subsidiou o julgamento no Supremo Tribunal Federal (STF) acerca da memorialidade dos indígenas em seus territórios e que ainda hoje lutam pela desintrusão de suas terras por colonos e fazendeiros. Como afirma o professor José Ribamar Bessa Freire: 
Os índios que apareceram na documentação desse catálogo não só passaram a existir, como também adquiriram voz. Eles falam e, algumas vezes, escrevem. E quando escrevem, reclamam, protestam, argumentam, registram as alianças feitas, desfeitas e refeitas, na luta pela terra e pela identidade. É possível ouvir o que dizem, recuperando suas palavras, registradas na documentação oficial aqui inventariada. (FREIRE, 2002, p. 13)

Portanto, a luta travada pelo grupo indígena Pataxó e registrada em arquivo do Estado brasileiro acabou se tornando um instrumento de luta por este grupo para a reapropriação de seu espaço físico, pela retomada de seu espaço de fala como também pela possibilidade de demandar ao Estado e suas autoridades. Como expõe Freire (2002, p. 14) "os índios do sul da Bahia escrevem em português, transformando a língua do colonizador em um instrumento de luta, num contexto em que suas terras abrigavam 'poucos índios selvagem"”.

Diante do que apresentamos até o presente momento, é possível afirmar que os registros documentários por si só têm poder e geram controle para um objetivo específico. O poder em questão pode beneficiar aquele que está na qualidade de possibilitar a acumulação documentária, ou aquele que foi objeto desta acumulação. Por exemplo, retomando o grupo indígena Pataxó, eles foram, num momento inicial, objeto deste controle e, mais tarde, ocorreu uma reconfiguração do uso da informação disponível com o objetivo de atender a interesses específicos para o grupo indígena. Segundo Ketellar:

Hasta ahora hemos encontrado registros como instrumentos de poder. Pero estos instrumentos tienen también um poder intrínseco. Los agentes públicos y privados no observan y describen meramente la realidad; ellos conforman a las personas, los eventos y el entorno en entidades que se ajustarán a sua categorizaciones y que son registables. Esta reificación social implica que no existen virtualmente otros echos que aquellos que están contenidos em los registros. (KETELLAR, 2007, p. 379)

Assim, o registro é a fonte indubitável da existência, por exemplo, de um determinado grupo indígena numa localidade do sul da Bahia, como no caso do grupo indígena Pataxó. Caso não existisse o registro e ele não tivesse sido conservado ao longo dos anos, não seria possível realizar a defesa por meio da memorialidade do território daquele povo.

Interessante também destacar que as informações que hoje povos indígenas demandam surgem em virtude da chamada sociedade da informação. Assim sendo, há uma estratégia de luta para permanecerem vivos e protagonistas, criando uma dinâmica própria para garantir e preservar direitos já conquistados que em muitos casos estão ameaçados por interesses escusos.

Quanto à manifestação contemporânea intitulada como sociedade da informação, vejamos a ideia presente na reflexão de Bolaño e quais complexidades tal sociedade esta 
envolvida, ainda mais quando relacionada ao fenômeno informacional indígena como problematizado no presente trabalho:

\begin{abstract}
A ideia de uma Sociedade da Informação, como a de Sociedade Pós-industrial, no seu tempo, refere-se a uma mudança real do capitalismo, fruto do esgotamento do padrão do desenvolvimento do pós-guerra. Ao contrário de esclarecer o movimento histórico concreto de passagem para um novo modelo de regulação (ou para a inexistência de regulação, como diriam outros) do sistema, essas noções têm uma função essencialmente ideológica. (BOLAÑO, 2004, p. 1)
\end{abstract}

Neste panorama da sociedade da informação, podemos afirmar que os povos indígenas começam a se empoderar em virtude do processo informacional, como no apoderamento de tecnologias de informação e comunicação (TICs) com o fito de realizar ações de registro documentário apresentando especificidades culturais que demarquem a culturalidade destes povos. Esta nova produção documentária pode representar certa guinada informacional para além dos paradigmas informacionais do Estado, como nos tempos do SPI e da própria FUNAI.

O próprio movimento de empoderamento dos povos indígenas frente ao fenômeno informacional pode apontar para um esgotamento das forças do Estado em manter vigente a ação coercitiva de vigiar e controlar seu território e grupos não hegemônicos, como os povos indígenas, num contexto de esgotamento capitalista e, evidentemente, do próprio modelo de Estado existente. Enquanto ao longo do século XX, a produção documentária foi produzida pelo próprio Estado, hoje povos não hegemônicos têm voz e conseguem produzir uma documentação que atenda às necessidades materiais e/ou simbólicas que venham a demandar.

Ainda discutindo a fase de esgotamento do capitalismo denominada como Sociedade da Informação, há de se realçar as peculiaridades do caso brasileiro e as incongruências da concentração de poder por elites que não desejam um aprofundamento do processo de democratização no país. Por este fenômeno, também cabe salientar o protagonismo indígena e o gerenciamento de acervos institucionais que detenham informações que sejam de interesse para os povos indígenas. A concentração e os mecanismos de controle são características fundamentais desta relação injusta e desigual entre elite e chamados subalternos.

Podemos citar ainda como limitação da participação das massas (leiam-se indígenas) no processo brasileiro, a baixa representatividade deste grupo específico da sociedade nos quadros do Poder Judiciário e Legislativo, como também a baixa representatividade dos povos indígenas em outras instâncias do Estado brasileiro. Por exemplo, apesar de ser uma discussão de outra natureza, até hoje não tivemos um presidente indígena na FUNAI, mesmo já tendo muitos 
índios com formação superior e plenas condições de preencher os requisitos que o cargo necessita.

No entanto, nas lutas políticas empreendidas nos dias de hoje, há perspectivas informacionais inclusive da construção de uma aldeia global televisiva (GIOVANNINI, 1987, p. 254). Neste sentido, a sociedade civil tem realizado discussões com o objetivo de criar uma programação em língua indígena, atendendo demandas dentro de um contexto de promoção a pluralidade e diversidade cultural que o Estado brasileiro procura incentivar por meio de políticas públicas.

O esforço que cientistas da informação devem ter para com o fenômeno informacional indígena é compreender em qual contexto ele está sendo produzido e para qual finalidade ele existe. Uma importante indagação reside se esta busca e criação autônoma de informação pelos próprios povos indígenas atendem a um interesse dos mesmos ou se, na verdade, o Estado os utiliza para outros fins, como sendo um verniz de autonomia, numa era de incertezas quanto ao futuro e garantia das terras indígenas.

Ainda discutindo o papel da Ciência da Informação neste contexto, concordamos com Borko quando afirma que:

Information science is that discipline that investigates the properties and behavior of
information, the forces governing the flow of information and the means of processing
information for optimum accessibility and usability. [...]. It is an interdisciplinary
science derived from and related to such field as mathematics, logic, linguistics,
psychology, computer technology, operations research, the graphic arts,
communications, library science, management, and other similar fields. (BORKO,
1968, p. 3)

Portanto, para compreendermos o fenômeno informacional indígena se faz necessário um esforço interdisciplinar que possa abarcar a construção deste novo paradigma de empoderamento de povos até pouco tempo passivos frente às ações realizadas pelo Estado e as iniciativas informacionais que grupos indígenas estavam envolvidos, no entanto, em voz ativa.

Os desafios que passam os povos indígenas em produzirem e disseminarem informação se faz de modo desafiador, ainda mais no tempo presente. Isto porque, como afirma Le Coadic (1996, p. 107), passamos por uma quarta revolução no uso da informação, de origem tecnológica, já “que assiste, de modo inexorável, à substituição do suporte de papel pelo suporte eletrônico." Ora, os suportes eletrônicos ou digitais são de grande magnitude e não temos ainda respostas plausíveis no que tange à utilização a salvaguarda perene destes novos suportes de 
informação. Talvez, possamos responder a questões tão desafiadoras com o conhecimento dos povos indígenas.

Neste sentido, ainda é possível afirmar que:

A ciência da informação surge por necessidades técnicas de recuperação das informações que haviam sido geradas em proporções geométricas principalmente durante a segunda guerra mundial, o que pressupõe organização, espaço para armazenagem, disseminação e uso para gerar novas informações. Não incorporar no seu nascedouro um arcabouço de conhecimentos teóricos que justifiquem um conhecimento novo é o que explica essa busca teórica basilar até hoje. Por outro lado, se ainda é dependente de teorias de outras ciências, justifica-se por ser relativamente jovem e, mais que isso, pela própria relação que mantém com algumas disciplinas que compõem as ciências sociais, por sua vez, também dependentes de teorias, mas nem por isso negada como ciências. (GARCIA, 2002, p. 64)

Uma disciplina que venha a contribuir para o aqui identificado fenômeno informacional indígena é a Antropologia, pelos estudos sobre a alteridade e ao atribuído diferente e/ou exótico. Deste modo, a Ciência da Informação deva não apenas estar dependente de teorias externas a ela própria, mas possa gerar novas perspectivas, a partir de uma visão informacional etnológica para uma maior compreensão dos fenômenos da informação para além dos circuitos hegemônicos, como aqueles produzidos no âmbito da ciência e tecnologia (C\&T).

\section{Uma breve introdução às informações de natureza etnológica}

É possível entrever nos últimos tempos o fomento de práticas informacionais de natureza etnológica não mais apenas por atores tradicionais como centros de documentação mantidos pelo Estado. Hoje, é observada a ação de atores autônomos que venham a (re) elaborar de maneira empoderadora a dinâmica nesses novos campos de trabalho, conhecimento e informação.

Desde já, há o entendimento de que as ações de natureza documentária são dinâmicas da política de memória da sociedade contemporânea que perfazem muitas vezes configurações que venham emergir relações de poder entre sujeitos do universo social, assim como também estão sendo colonizados por novas (re) configurações de ação documentária. Assim:

Documentar, registrar, clasificar, avalar la materialidad de los restos y visibilizar estos signos para el presente, son procesos que se articulan al desarollo de una política de la memoria inmersa em las dinámicas del poder de las sociedades contemporáneas. (BEDOYA; WAPPENSTEIN, 2011, p. 12)

As formações de centros de informação de natureza etnológica desenvolvidas pelos próprios ameríndios significam o fomento de novas práticas documentárias que se inserem nas 
dinâmicas de poder da sociedade hodierna, formações que permitem novas reflexões sobre o papel do arquivo, do documentar e da informação para estratos antes excluídos de tais práticas.

Preambularmente, serão identificadas instituições existentes hoje que possuem por escopo informações de natureza etnológica não estatal: Museu Kuahí dos Povos Indígenas do Oiapoque, Centro de Formação e Documentação Wajãpi, Centro de Documentação e Pesquisa Indígena, Centro Timbira de Ensino e Pesquisa Pënxwyj Hempejxá, Centro Indígena de Formação Raposa Serra do Sol, Associação Indígena Kisedje, Centro de Cultura Kuikuro e Centro de Cultura Mawo.

Cada uma das instituições supracitadas representa a consolidação de esforços de povos indígenas das mais diversas regiões do Brasil em realizar ações informacionais autônomas com o objetivo de valorizar a sua cultura e produzir desdobramentos documentários para além daqueles conhecidos outrora quando da ação, por exemplo, de instituições de memória do Estado brasileiro.

No ano de 2013 temos a realização de um primeiro encontro em que se reuniram 10 organizações indígenas e indigenistas para tratar diversas questões que pudessem apontar para soluções numa melhora na gestão administrativa/informacional das instituições participantes. Vejamos os três objetivos principais:

1) Realizar um diagnóstico da situação dos acervos culturais constituídos, guardados e geridos em centros de documentação, de formação, de cultura e museus geridos por comunidades e organizações indígenas e indigenistas em diferentes locais da Amazônia brasileira, buscando identificar a natureza desses acervos, sua situação atual, potencialidades e fragilidades;

2) Apresentar e discutir a possibilidade de uso de dois software de gestão de acervos, em uso pelo Museu do Índio (IcaAtom e PHL) e sua aplicabilidade para acervos geridos por povos e organizações indígenas e formados por itens de seus patrimônios culturais, buscando a criação de vocabulários integrados e controlados que permitam interface entre essas instituições;

3) Propor e discutir a criação de uma rede de instituições (centros de formação, documentação, de cultura e museus indígenas) para atuar de forma articulada na preservação de acervos e documentos culturais indígenas, na elaboração de protocolos, com critérios de adesão e formas de cooperação técnica. (GESTÃO, 2013, p. 3)

Um ponto de problematização talvez seja o entendimento da existência desses centros de formação, de documentação, de cultura e museus indígenas no Brasil. Qual é o objetivo central dessas instituições? Será uma relação de saber e poder calcadas nos princípios experimentados pelo Estado Moderno ao longo da sua existência? Ou será que a emergência inovadora desses centros significará uma ação continuada mais ampla, de cunho decolonial, 
que fará surgir novos conhecimentos de combate à hegemonia ocidental sobre a gestão de acervos e da informação em circulação de natureza etnológica?

Creio que a passagem abaixo poderá complexificar melhor de que maneira saberes indígenas e ações documentárias de natureza etnológica podem se cruzar por meio de instrumentos técnicos e por uma certa (re) configuração institucional quando da fundação de instituições de memória:

\footnotetext{
Saberes que se constituem em conhecimento técnico. Reapropriado e convergido para fins de coletividade comunitária, somente possíveis pelo reconhecimento e emprego da técnica em meio às necessidades de registro, salvaguarda e reprodução de elementos informacionais e documentais presentes no processo de individuação dos povos indígenas. Com efeito, o desenvolvimento de instituições de natureza documentária pelos povos indígenas possui implicações maiores do que aquelas estabelecidas na relação típica de saber/poder, já que essas construções intelectuais realizadas pelos ameríndios representam a possibilidade de novas configurações institucionais e, até mesmo, de novas expressões de um dado povo. (PIMENTA; MELLO, 2017, p. 171-172)
}

Devido às próprias especificidades dos saberes indígenas e também à possibilidade de novos conhecimentos a serem nutridos e consolidados, os povos indígenas quando do desenvolver de novas instituições, sejam organizações de natureza política/reivindicatória, sejam aquelas de natureza documentária (por que não, também reivindicatória) estabelecerá novas possibilidades e reconfigurações frente às demandas por acesso à informação, à terra, à saúde e outras demandas que venham escavar a luta por condições dignas de existência, assim como também por um aprofundamento do processo democrático num contexto de cidadania ativa.

Outra discussão possível de ser aventada diz respeito à ruptura de pensamento na formação da identidade cultural na pós-modernidade em que as sociedades modernas estão em permanente mudança e deslocamento. Assim:

As sociedades modernas, argumenta Laclau, não têm nenhum centro, nenhum princípio articulador ou organizador único e não se desenvolvem de acordo com o desdobramento de uma única "causa" ou "lei". A sociedade não é, como os sociólogos pensaram muitas vezes, um todo unificado e bem delimitado, uma totalidade evolucionárias e partir de si mesma, como o desenvolvimento de uma flor a partir de seu bulbo. Ela está constantemente sendo "descentrada" ou deslocada por forças fora de si mesma. (HALL, 2005, p. 16-17)

Se antes as sociedades indígenas estavam plasmadas em processos sociais de baixa dinamização social em virtude do não encontro com a sociedade envolvente, também autointitulada como civilizada, com o contato perene, há um deslocamento de padrões culturais estabelecidos preteritamente. $\mathrm{O}$ fomento de centros de documentação de natureza etnológica 
pode vir a ser uma luta que povos indígenas travam na manutenção de sua cultura, sua especificidade e seu modo de ser.

\section{Ação informacional no processo de documentação}

Quanto à contemporaneidade e a chamada sociedade da informação, podemos visualizar que uma das principais características é a importância dada à informação e ao modo como ela é produzida, registrada, disseminada, transmitida e recebida pelos agentes que interagem em sociedade. Conforme explana Le Coadic, a informação:

[...] comporta um elemento de sentido. É um significado transmitido a um ser consciente por meio de uma mensagem inscrita em um suporte espacial-temporal: impresso, sinal elétrico, onda sonora, etc. Essa inscrição é feita graças a um sistema de signos (a linguagem), signo este que é um elemento da linguagem que associa um significante a um significado: signo alfabético, palavra, sinal de pontuação. (LE COADIC, 1996, p. 5)

A importância da informação foi sendo alterada e reestruturada ao longo do tempo, porém, nos dias de hoje, há um superdimensionamento deste conceito utilizado com frequência na contemporaneidade. Assim, como as sociedades entendem o fenômeno informacional dependem muito da forma como ela é apreendida do ponto de vista hermenêutico. Segundo Machado:

$\mathrm{Na}$ linguagem comum, o conceito de informação está sempre ligado ao significado e é usado como sinônimo de mensagem, notícia, fatos e ideias que são adquiridos e passados adiante como conhecimento. $\mathrm{O}$ homem procura manter-se informado sobre a vida política do país e do mundo, sobre os progressos da ciência, pelo simples prazer de saber. Ao uso comum do conceito de informação exprime uma concepção antropomórfica do vocábulo. (MACHADO, 2003, p. 15)

Assim sendo, é possível afirmar que os indivíduos em sociedade possuem a necessidade de obterem informações para se sentirem atualizados do que os circundam na vida cotidiana e prosaica. Todavia, o significado e a necessidade deste uso da informação são muito relativos e dependem muitas vezes da realidade circunscrita dos atores sociais em interação.

Este uso de informações também necessita de certos suportes para que possam transmitir às futuras gerações os conhecimentos adquiridos na perpetuação da espécie. Diferente dos animais, os seres humanos nascem dentro de estruturas de aprendizagem e comportamento que existiam antes de nós e as utilizam para delas extrair informações sobre a realidade social e o lugar que nele ocupam. 
Para o armazenamento deste estoque de informação de vulto, sentimos a necessidade desde a Antiguidade da construção de repositórios para o fim de salvaguardar esta cultura acumulada por longo tempo. A permanência e a conservação são essenciais para a continuidade de uma cultura. Logo, os seres humanos poderão se beneficiar dos conhecimentos produzidos por outros e deverão ter um tipo singular de armazenagem para transmitir esses benefícios através dos tempos.

Seguindo a concepção do sociólogo Émile Durkheim sobre o funcionamento da vida em sociedade, é possível identificar que a informação possui elementos que a caracterizam como um fato social, pois tem uma das suas principais características: a coerção. Vejamos:

Chegamos assim a conceber de maneira precisa qual o domínio da sociologia, o qual não engloba senão um grupo determinado de fenômenos. O fato social é reconhecível pelo poder de coerção externa que exerce ou é suscetível de exercer sobre os indivíduos; e a presença deste poder é reconhecível, por sua vez, seja pela existência de alguma sanção determinada, seja pela resistência que o fato opõe a qualquer empreendimento individual que tenda a violentá-lo. (DURKHEIM, 1978, p. 8)

$\mathrm{Na}$ hodiernidade, há uma imperiosa necessidade que extrapola a alçada dos indivíduos em realizar uma acumulação documentária com o fito de documentar a existência dos seres humanos de forma perene, ou enquanto existirem os centros de documentação para que venham a garantir a salvaguarda deste material acumulado ao longo do tempo. Devido à própria peculiaridade do fato social a partir da perspectiva durkheimiana, a informação adquire uma exterioridade que independe da existência dos indivíduos, já que a sua formação é precedida pela própria vida em sociedade.

Os profissionais da informação, como bibliotecários, arquivistas e documentalistas, em geral, têm como dever estudar o documento em um contexto bem definido, tanto em relação ao suporte que sustenta a informação inscrita, quanto em relação à instituição que o abriga. $\mathrm{O}$ suporte físico, como o papel e a película, é certamente tangível e passível de manipulação em seu conteúdo.

Diante do exposto, ao nos depararmos ao fenômeno informacional indígena e o seu processo de documentação, é possível inferir que os povos indígenas também enfrentam o desafio de documentar sua própria cultura. Logo, os problemas clássicos encontrados por documentalistas também são identificados por estes povos, já que há um processo crescente de autonomia de indígenas, não sendo mais agentes passivos da construção documentária, mas sim os próprios construtores de seus repositórios. 
Partindo da definição clássica da documentalista Suzanne Briet (BRIET, 1951 apud MACHADO, 2003, p. 25), "documento é toda base de conteúdo informacional, fixada materialmente e suscetível de estudo, prova ou confronto". Sendo assim, o documento possui por natureza um valor probatório para que possa validar, a título de exemplo, certas manifestações culturais num determinado espaço temporal.

No entanto, não é qualquer manifestação material que indicaria o que seria um documento. Há a necessidade de se passar por alguns processos legitimadores, como o processo de documentação, para aquele bem se tornar de fato um documento. Vejamos:

Is a star a document? Is a pebble rolled by a torrent a document? Is a living animal a document? No. But the photographs and the catalogues of stars, the stones in a museum of mineralogy, and the animals that are cataloged and shown in a zoo, are documents. (BRIET, 1951, p. 10)

Assim, a documentação apenas existirá quando os registros linguísticos indígenas, por exemplo, fizerem parte de um sistema de informação ou forem realizados produtos, como gramáticas ou dicionários, para que possam materializar e disponibilizar aquela inscrição adquirida em pesquisas feitas em campo.

A documentação, segundo Briet, terá a responsabilidade de gerar frutos importantes, como a dinamização na cultura moderna. As atividades técnicas típicas da documentação, como a seleção e a análise documentária, produzirá uma massa documental que fomentará outras atividades humanas. Nos termos de Briet:

Let us admire the documentary fertility of a simple originary fact: for example an antelope of a new kind has been encountered in Africa by an explorer who has succeeded in capturing an individual that is then brought back to Europe for our Botanical Garden [Jardin des Plantes]. A press release makes the event known by newspaper, by radio, and by newsreels. The discovery becomes the topic of an announcement at the Academy of Sciences. A professor of the Museum discusses it in his courses. The living animal is placed in a cage and catalogue (zoological garden). Once it is dead, it will be stuffed and preserved (in the Museum). It is loaned to an Exposition. Is is played on a soundtrack at the cinema. Its voice is recorded on a disk. The first monograph serves to establish part of a treatise with plates, then a special encyclopedia (zoological), then a general encyclopedia. The works are cataloged in a library, after having been announced at publication (publisher catalogues and Bibliography of France). The documents are recopied (drawing, watercolors, paintings, statues, photos, films, microfilms), then selected, analyzed, described, translated (documentary productions). The documents that relate to this event are the object of a scientific classifying (fauna) and of an ideologic [ideólogique] classifying (classification). Their ultimate conservation and utilization are determined by some general techniques and by methods that apply to all documents - methods that are studied in national associations and at international Congress. The cataloged antelope is an initial document and the other documents are secondary or derived. (BRIET, 1951, p. 10-11) 
Chega a ser surpreendente que a coleta de um antílope possa ter tamanha reverberação para a sociedade. Briet tenta demonstrar com seu exemplo que só foi possível esta socialização do conhecimento da descoberta do antílope devido à atividade de documentação por qual esta coleta passou.

Outro ponto chave para a compreensão da documentação para Briet é a relação entre o documento inicial e a documentação derivada. Aquele animal simplesmente foi empalhado num museu porque já existiam documents secundary or derived que sustentavam a sua existência num determinado acervo museológico ou em exposição.

Se o documento, na definição modelar de Briet, possui em sua constituição uma natureza probatória, o mesmo vale para o papel da documentação na salvaguarda de línguas indígenas em perigo de extinção, além da conjuntura histórica que nos obriga como indivíduos conscientes do papel histórico-social a ser exercido, a reparar os danos causados a povos tão apenados que foram e, continuam sendo, os povos indígenas.

\section{Considerações finais}

Os desafios a serem enfrentados que permeiam o fenômeno informacional indígena são de grande magnitude. Enquanto a sociedade ocidental produz registros em suportes de longa duração, como o papiro há séculos atrás, hoje populações indígenas com baixa tradição escrita tem realizado esforços para documentar a sua cultura. No entanto, as questões informacionais com as quais os povos indígenas tem se deparado talvez sejam as mesmas sobre as quais cientistas da informação têm enfrentado. Tal fenômeno ocorre em virtude das novas configurações documentárias de natureza étnica, como no fomento de centros de documentação em áreas indígenas e gerenciados pelos próprios.

Outro fator de destaque aos estudos informacionais indígenas é a importância que os repositórios existentes e mantidos pelo Estado brasileiro, como os arquivos indigenistas que estão acolhidos pelo Museu do Índio, possuem na comprovação da memorialidade da ocupação de indígenas. A recuperação da informação representa mais do que o acesso à terra, mas a sobrevivência no seu lugar de origem.

A possibilidade de intersecções entre as ações de documentação de natureza étnica, como a fomentada por povos indígenas, e a expertise do Estado no processo documentário, 
pode gerar dividendos que venham a reelaborar práticas documentárias consolidadas e ganhos para o aprofundamento das lutas indígenas.

\section{Referências}

BEDOYA, Maria Elena; WAPPENSTEIN, Susana. (Re) Pensar el archivo. Íconos: Revista de Ciencias Sociales, n. 41, p. 11-16, sep. 2011.

BOLAÑO, César Ricardo Silveira. Sociedade da Informação, reestruturação produtiva e economia do conhecimento. Universidade e Sociedade, Brasília, DF, v. 14, n. 33, p. 186190, 2004.

BORKO, Harold. Information science: what is it? American Documentation, Washington, v. 19, n. 1, p. 3-5, jan. 1968.

BRADFORD, Samuel Clement. Documentação. Rio de Janeiro: Fundo de Cultura, 1961.

BRIET, Suzanne. What is documentation? Paris: Éditions Documentairs Industrielles et Techniques, 1951.

DELMAS, Bruno. Arquivos para que?: textos escolhidos. São Paulo: Instituto Fernando Henrique Cardoso, 2010.

DURKHEIM, Émile. As regras do método sociológico. São Paulo: Nacional, 1978.

FREIRE, Carlos Augusto da Rocha. Introdução. In: FREIRE, Carlos Augusto da Rocha (Organizador). Memória do SPI: textos, imagens e documentos sobre o Serviço de Proteção aos Índios (1910-1967). Rio de Janeiro: Museu do Índio, 2011. p. 11-13.

FREIRE, José Ribamar Bessa. Prefácio. In: MUSEU do Índio. Povos indígenas no sul da Bahia: Posto Indígena Caramuru-Paraguaçu (1910/1967). Rio de Janeiro: Museu do Índio, 2002. p. 13-17.

GARCIA, Joana Coeli Ribeiro. Conferências do Georgia Institute of Technology e a Ciência da Informação: “de volta para o futuro". Informação \& Sociedade: estudos, João Pessoa, v. 12, n. 1, p. 54-66, 2002.

GESTÃO DE ACERVOS CULTURAIS EM CENTROS DE FORMAÇÃO, DE DOCUMENTAÇÃO, DE CULTURA E MUSEU INDÍGENAS NO BRASIL, 2013. Documento base do seminário temático. Saquarema: Museu do Índio, 2013.

GIOVANNINI, Giovanni. Evolução na comunicação: do sílex ao silício. Rio de Janeiro: Nova Fronteira, 1987.

HALL, Stuart. A identidade cultural na pós-modernidade. Rio de Janeiro: DP\&A, 2005.

KETELLAR, Eric. Gestión de registros y poder social. In: MCKEMMISH, Sue [et. al.]. Archivos: gestión de registro en la sociedad. Cartagena: 3000 Informatica, 2007. p. 379-404. 
LE COADIC, Yves-François. A Ciência da Informação. Brasília: Briquet de Lemos, 1996.

MACHADO, Ana Maria Nogueira. Informação e controle bibliográfico: um olhar sobre a cibernética. São Paulo: Editora UNESP, 2003.

MOREIRA NETO, Carlos de Araújo. Centro de documentação etnológica da FUNAI. Arquivo \& Administração, Rio de Janeiro, v. 7, n. 2, p. 12-15, maio/ago. 1979.

OLIVEIRA, João Pacheco de. Cidadania e globalização: povos indígenas e agências multilaterais. In: LIMA, Antonio Carlos de Souza; BARROSO-HOFFMANN, Maria. Além da tutela: bases para uma nova política indigenista. Rio de Janeiro: Contra Capa Livraria/LACED, 2002. p. 105-119.

PIMENTA, Ricardo Medeiros; MELLO, Rodrigo Piquet Saboia de. Olhares e práticas convergentes da informação: algumas reflexões sobre Gilbert Simondon, interdisciplinaridade e saberes indígenas. Revista ECO-Pós, Rio de Janeiro, v. 20, n. 1, p. 170-183, 2017.

RIBEIRO, Darcy. A política indigenista brasileira. Rio de Janeiro: Ministério da Agricultura, Serviço de Informação Agrícola, 1962. 